\title{
LEADERSHIP TRANSCENDING BORDERS: BUILDING BRIDGES to Integrate TeChniCAL AND Professional KNOWLEDGe
}

\author{
William Schell ${ }^{1,2}$, Bryce Hughes ${ }^{1,2}$, John Donald ${ }^{3}$, Tom Goldfinch ${ }^{4}$, Anthony Kadi $^{4}$, Emily Moore ${ }^{5}$, \\ Doug Reeve, Cindy Rottmann ${ }^{5}$, and Patricia Sheridan ${ }^{5}$ \\ ${ }^{1}$ Montana State University, ${ }^{2}$ Montana Engineering Education Research Center, ${ }^{3}$ University of Guelph, \\ ${ }^{4}$ University of Sydney, ${ }^{5}$ University of Toronto \\ wschell@montana.edu
}

\begin{abstract}
Engineering knowledge is characterized by an artificial "border" that distinguishes technical expertise from the professional skills needed to solve society's most pressing problems. Scholars of engineering leadership argue that students who are provided opportunities to blur that distinction and integrate their technical and professional training are better prepared for interdisciplinary and transnational engineering work. This "Lightning Talk" session brings together engineering leadership researchers from universities in Australia, Canada, and the United States to explore an array of approaches to understanding and developing engineering leadership. Best practices are presented followed by a panel discussion of the implications for internationalizing work on engineering leadership.
\end{abstract}

Keywords: engineering leadership, leadership development, engineering identity

\section{INTRODUCTION}

Many of the greatest challenges facing society today require technical solutions that can only be created through collaboration within interdisciplinary teams. For these collaborations to effectively harness the capabilities of groups that may not normally work together, effective technical leadership must be deployed. We argue that engineers are well positioned to provide this leadership, but often not well prepared. Thus, the need for engineering leadership (EL) education.

\section{BACKGROUND AND LITERTURE}

The concept of engineering leadership is a relatively new one in engineering education, with most publications on the topic and formal programs to develop it appearing in the last fifteen years [1]. In fact, a 2009 formal review of engineering leadership programs found only eight worthy of consideration for best practices [2]. The past decade has brought a flurry of activity around EL education, ranging from development of an EL focused division in ASEE, to dedicated EL conferences in Canada and the U.S., to a growing number of papers on EL presented in a variety of engineering education conferences around the globe (e.g. AAEE, ASEE, and CEEA).

This activity reflects growing recognition of the importance of EL and is part of a movement toward incorporating curricular materials to develop engineers who meet the broad needs of society. There are a number of pressures driving this change, including changes in accreditation criteria, calls from seminal reports such as the Engineer of 2020, and evidence from engineering graduates who indicate professional-skills are often what engineers find most important in the workplace [3].

\section{GLOBAL PERSPECTIVES ON ENGINEERING LEADERSHIP}

Each school involved in this work has their own approach to developing engineering students who are ready to lead, driven in part by the cultural and accreditation differences in each country and the unique setting and demands of each school. While each of the following approaches is unique, they all share not only a common goal, but similar groundings in applied research and integration of industry perspectives. The following sections explore these approaches.

\subsection{Guelph - Identifying Influences on Leadership Content in the Engineering Curriculum}

At the University of Guelph, we know that engineers must contribute to society in more than simply technical ways. As such, we recognize that it is important for engineering educators to articulate the nature of leadership programming in the curriculum. In order to articulate this nature, in partnership with colleagues at the University of Toronto, we have undertaken a systematic study to describe the nature, content and context of educational efforts to develop engineering leadership at selected engineering schools in Canada and the United States. To support this description, a taxonomy for describing engineering leadership in the context of an Academic Plan 
[4] was developed. This framework uses seven elements (purpose, content, sequence, learners, instructional processes, instructional resources, and evaluation) to review the activities of engineering leadership programs while considering both internal (e.g. faculty mission / vision; student characteristics) and external (e.g. market forces, accreditation) influences.

Perhaps not surprisingly, given the lack of a unified definition of engineering leadership, findings show that a wide variety of approaches, materials and resources are utilized in engineering leadership curricula. It appears that program designers and instructors understand engineering leadership in a myriad of different ways, and this is reflected in the content they select and the specific texts, theories and frameworks they use to communicate that to students. For example, elements of purpose tend to explicitly seek to develop leadership competencies in engineering students and often start with a baseline in leadership theory. However, even within this commonality, offerings varied from traditional lecture to experiential and those focused on personal leadership to leading teams in the future workplace. More details on these findings can be found in our earlier work [5-7]. This portion of the panel discussion will focus on application of the framework to inform EL education development and practice.

\subsection{Sydney - Motivating and Integrating Engineering Leadership}

A recent report from Development Dimensions International [8] analyzed 15,000 leaders across 300 organizations, 20 industries and 18 countries. One of their findings was that an engineering degree produces the weakest set of leadership skills when compared with other degrees. This is not surprising to engineering educators, as very few degree programs include leadership theory or leadership development. The University of Sydney is changing that in through two different approaches discussed below. These approaches include both promoting the importance of and improving curricular integration of EL.

3.2.1. Faculty of Engineering Leadership Scholarship Program. The leadership scholarship is the most prestigious scholarship offered by the faculty for students commencing an undergraduate degree from high school. The minimum requirements to apply include an Australian Tertiary Admission Rank (ATAR) ${ }^{1}$ of 98.00 or higher. Applicants are shortlisted from a series of online questions. Shortlisted applicants are invited to a scholarship selection day which involves a series of group activities and individual interviews. Only 12 scholarships per year are awarded from a total commencing cohort of over 1500

\footnotetext{
${ }^{1}{ }_{1}$ The Australian Tertiary Admission Rank (ATAR) is a number between 0.00 and 99.95 that indicates a student's position relative to all the students in their age group (i.e. all 16 to 20 year olds in the state of New South Wales). Universities use the ATAR to help them select
}

students. The main aims of the scholarship are to cultivate the next generation of engineering leaders while attracting the best and brightest students to come and study at the University of Sydney. An additional aim is to increase engagement with leading engineering organizations through having students undertake multiple placements during the program - and for these organizations to help fund the program. Scholarship recipients enjoy the following benefits:

- AUD $\$ 19,500$ per annum for 4 years, divided into AUD\$12,500 cash and \$6,500 leadership development activity funding ${ }^{2}$

- "Faculty of Engineering Leadership Scholarship" printed on their official transcript for each year that they remain in the program

- 3 placements: year 1 can be either a self-organized industry placement of 4 weeks full-time or an academic placement involving an international leadership development project at Penn State University. The year 2 and year 3 placements are faculty organized industry placement of 8 and 12 weeks duration, respectively.

- Leadership development training: Scholars are provided with 200 hours of structured leadership development opportunities over the 4 years of their degree, which are divided into 4 categories:

$\circ \quad$ Leadership Theory (core) - 50 hours delivered by blended learning workshops and industry talks organized by the faculty specifically for the program

○ Leadership Theory (elective) -50 hours scholars choose from a variety of online and/or face to face courses or other activities

○ Leadership Practice (core) - 50 hours opportunities for scholars to get involved in running faculty activities on campus such as peer mentoring schemes, organizing open days or industry nights, and running clubs and societies

○ Leadership Practice (elective) - 50 hours any activity on campus or off that allows students to practice their leadership skills and further develop their abilities.

Completion of leadership development training hours has quarterly milestones which must be met for scholars to receive their quarterly payments. Figure 1 shows that the theory components are largely completed in years 1 and 2,

students for their courses and admission to most tertiary courses is based on your selection rank as well as other criteria, typically.

2 Tuition fees for domestic students in a Bachelor of Engineering (Honours) course in 2020 are AUD\$9,527 per annum for comparison. 
and practice components are more heavily concentrated in years 3 and 4.

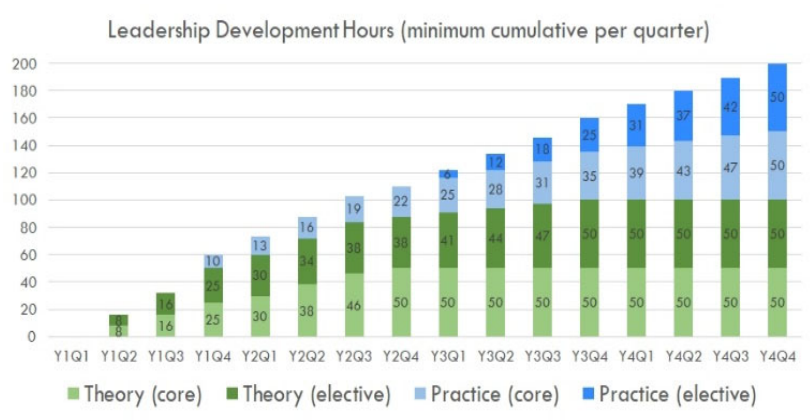

Figure 1 - Leadership Scholarship Development Hours

Since starting in 2017, the median ATAR for commencing students in the entire faculty has increased significantly - from 2012 to 2018, the median ATAR for commencing domestic students increased from 90.6 to 94.3 across the faulty and the proportion of students with an ATAR of 98 or higher rose from $15 \%$ to $28 \%$. There are various factors that may have led to this increase, including the introduction of the leadership scholarship program the vast majority of high achieving students who apply for the scholarship enroll to study at Sydney University even if they are unsuccessful in gaining the scholarship. Engineering employers have been delighted with the quality of students undertaking placement - many students have gained graduate employment through the program; while some students have gone onto further study (another good outcome for the University). The first cohort of leadership scholars are nearing graduation - we look forward to tracking these students to look for other indicators of program success.

3.2.2. Integrated Engineering - Formation of Professional Identity and Leadership Capacity. The Integrated Engineering Program at the University of Sydney is a series of four units of study, one per year of study, designed to develop and assess students' capacity to connect technical knowledge and skills to complex, realworld applications. As a core program, the combined four units of study are delivered to around 2,500 undergraduate students per year. The program moves students from an introduction to design, innovation and practice, through the realities of business and economics, to understanding and adapting to user needs, and finally on to leadership and influence in engineering. The $4^{\text {th }}$ unit, the focus of this talk, seeks to: 1) Develop student's abilities with respect to research, leadership and influencing through self-guided learning and assessments; and, 2) Develop student's capacity to navigate complexity and drive change in the fast-moving world of engineering innovation.

The semester long project and learning activities draw on Global Grand Challenges $[9,10]$ and task students with analyzing the potential impact of a grand challenge on an engineering entity of their choosing, and developing an appropriate policy-level response. A sequence of structured and self-directed learning activities, both independent and team-based, guide students through the process of identifying the issues (using a SWOT analysis), examining the current, proposed, and informal directions of the chosen entity, and developing a compelling recommendation for change (or no change) dictated by the analysis. The final task of the unit is a self-evaluation of the likely success of their own recommendation in comparison with those of their peers, and their leadership capacity with reference to a published leadership framework [11].

Over two semesters of running the unit, three outcomes are apparent among a majority of students:

- Students compartmentalize concepts of leadership and do not readily draw on their technical domain knowledge to inform recommendations;

- students readily identify flaws/strengths in their own argument for change with the opportunity to compare and critique their peers; and,

- students' reflections on their own leadership capacity remain focused on student team leadership and completing the immediate task, rather than on leadership in the context of engineering practice.

The above observations have been recorded through assessment outcomes and end-of-semester teaching team debriefings. Deeper analysis of assessment submissions and reflective reports is now underway. Focus groups are also planned for the first half of 2020 to more deeply explore how students view leadership in an engineering context and their formation of leadership identity.

\subsection{Montana State - Research to Improve Engineering Leadership Education}

The research team at Montana State University is engaged in a multi-year effort to understand engineering leadership in the context of undergraduate engineering students. The goal of this research is to inform improved approaches for engineering leadership education by embedding leadership into the very identity of engineering. Figure 2 shows our concept of an engineering leadership

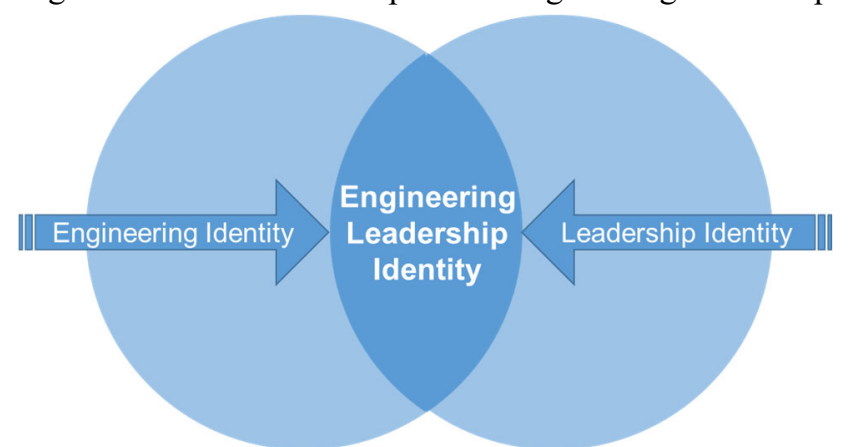

Figure 2. Intersection Creates Engineering Leadership 
identity, which postulates its existence at the intersection of engineering identity and leadership identity.

To investigate how engineering identity and leadership identity within undergraduate students behave at this intersection, the project employed both quantitative and qualitative research approaches.

The quantitative phase of the project utilized two national data sets of college students in the United States. The first data set came from a selection of questions taken from the National Survey of Student Engagement (NSSE) at the University of Indiana. This data set was utilized to better understand the leadership experiences of undergraduate students, and how these experiences differ for engineering students and their peers in other fields. For this study, a group of institutions from the 2015 administration of the survey were selected to participate in a pilot study with a new module to measure student leadership experiences, which randomly sampled 6547 students $(2.1 \%)$ at these 21 different bachelor's-granting institutions. The second data set came from the 2009 Freshman Survey (TFS), and subsequent 2013 College Senior Survey (CSS) follow-up, administered by the Cooperative Institutional Research Program (CIRP) at the Higher Education Research Institute (HERI) at UCLA. Student responses to the CSS were matched to their responses to the TFS to produce a longitudinal dataset. The 2013 CSS dataset includes student responses from 94 colleges and universities, totaling 17,667 students, of whom 918 indicated an engineering major at the end of their fourth year of college.

Through analysis of these data, a number of activities were found to be impactful on the development of an engineering leadership identity. Examples included: working with diverse others, making connections between co-curricular activities and coursework, inclusion of leadership in coursework, feedback from activity advisors, reflective learning activities, peer work, and interaction with faculty. A more complete view of these impacts appears in our earlier work [12-16].

The qualitative phase of the project collected data through focus groups at MSU, the University of Colorado - Boulder, and the University of Texas Arlington. Focus groups of approximately one hour utilized a protocol that explored three distinct areas of student perceptions: engineering identity, leadership identity, and engineering leadership identity. Overall, twenty focus groups were conducted which included 64 total students representing 17 different engineering majors. This resulted in over 22 hours of recorded material and 362 pages of transcripts. While analysis of this data continues, initial findings have highlighted the importance of experiences that develop both technical and interpersonal skills as they influence identity. In addition, this data has highlighted a seemingly widespread and persistent student belief that engineering leadership can come only after a high level of competence as an engineer is achieved, a belief that seems consistent with the Technical Mastery orientation of engineering leadership from Toronto's earlier work [17]. More complete discussion of findings from this data are in our earlier work [18-20].

The findings from both the quantitative and qualitative phases of the project are now providing a foundation for curricular interventions. These interventions are designed to enhance the development of engineering leadership identity. Currently, different interventions are being tested with both first year and fourth year students. The panel presentation will include discussion of the findings from these tests.

\subsection{Toronto - From Entrepreneurial Start up to Institution: Building Capacity for Engineering Leadership Research}

At Troost ILead of the University of Toronto, we realize our vision-engineers leading change to build a better world - through three pillars: programing, research and outreach. Our contribution to this panel focuses on one of these pillars - engineering leadership research. In particular, we discuss key findings from two thriving research streams rooted in distinct disciplinary traditions: 1) the Team Effectiveness Learning System (TELS) and 2) the Engineering Leadership Project (ELP). Figure 3 provides a schematic of the modes of inquiry underlying the two projects, building respectively on engineering design and social science traditions. Because these projects are embedded in the maturation of our institute, rather than isolated lines of inquiry, we use this opportunity to trace our organizational development from entrepreneurial startup to formalized institution - established by our founding

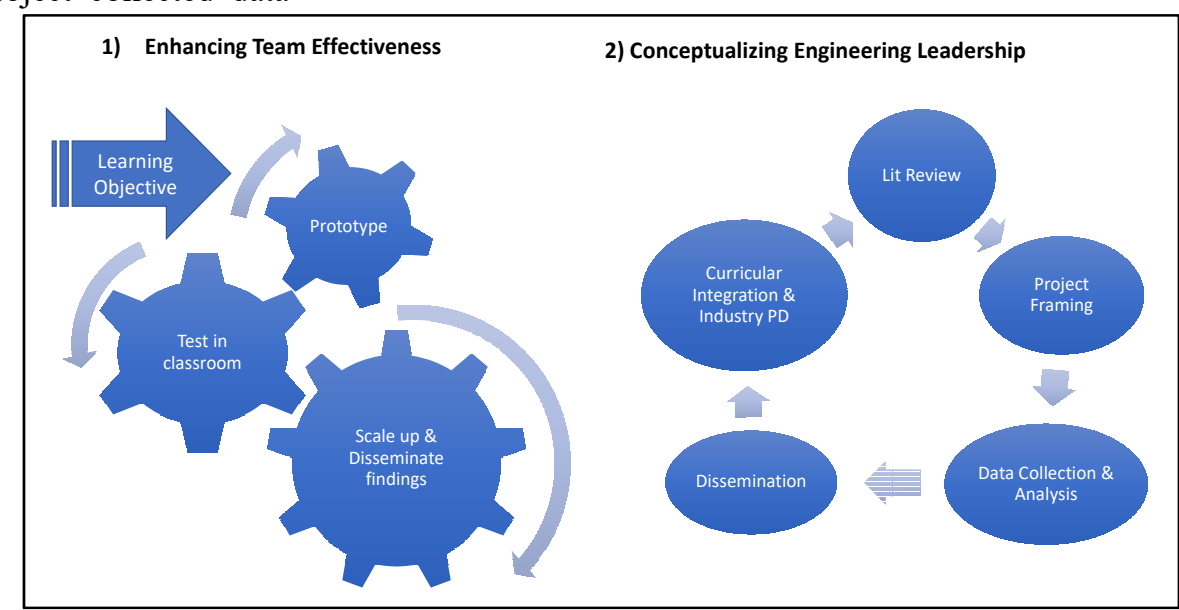

Figure 3. Two models for Engineering Leadership Research \& Practice 
Director-Professor Doug Reeve, and consolidated by our current Director-Professor Emily Moore.

In 2011, Troost ILead (originally Leaders of Tomorrow) began integrating research into our growing co-curricular leadership program through two key projects-one supporting the development of team effectiveness in undergraduate students (TELS), and the other examining how engineers lead in workplace contexts (ELP). While the two projects were initially intended to enhance our co-curricular programing efforts, they have since taken root as distinct institutional pillars-research and curricular integration. Over the past nine years we have conducted research on teamwork in engineering education contexts [21-27], engineers' leadership orientations [17, 28-31], engineers' career paths [32-41], ethics and equity in engineering education [42-45], and engineering leadership program evaluation [32, 46-49]. For the purpose of this panel, however, we focus on two lines of inquiry that have matured alongside our transformation from cocurricular leadership development program to engineering leadership institute:

1. How can undergraduate engineering students develop their team effectiveness competencies?

2. How do engineers lead in workplace settings?

The first of these questions began as a doctoral research project, with Professor Patricia Sheridan and her two thesis supervisors-Professor Doug Reeve and Professor Greg Evans - as the trailblazers. Over the course of her doctoral studies, Patricia developed, tested, iterated and scaled up the Team Effectiveness Learning System (TELS) - through a process rooted deeply in engineering design traditions. She began with a problem to be solvedengineering students are placed in teams without being supported in their teamwork development. Not only did she develop, test and iterate her system to solve this problem as part of her dissertation; she has also successfully integrated teamwork learning into 24 technical and design courses. Every first-year engineering student at the University of Toronto now receives a minimum of 7 hours of instruction in leadership and teamwork. TELS has been used in over 18 different courses in the past two years, including one course in another Faculty. Along the way, Patricia has disseminated research findings to scholarly and institutional audiences [e.g. 21 - 27].

The second of these projects-the Engineering Leadership Project-was inspired by Professor Doug Reeve's desire to collect “engineering leadership best practices" from industry to support our curricular and cocurricular programing. He assembled a team of social scientists to frame and carry out the research while using his knowledge of industry and university structures to build capacity for an emerging field. The engineering leadership Community of Practice (COP) - now in its $7^{\text {th }}$ year-is an innovative funding stream, participant sample, feedback mechanism, and professional development vehicle all in one dynamic network. This community of engineeringintensive organizations supports our research by sharing their professionally grounded practices, informing our findings, financially supporting our efforts and engaging in evidence-based learning opportunities at our bi-annual COP conferences. In contrast to the TELS project, which is rooted in problem solving, testing, iteration and scaling, ELP is rooted in social science theory and methodologies - with knowledge mobilization and curricular integration as one of many research outcomes. To date, we have run 10 COP conferences, conducted upwards of 40 lunch and learn sessions for COP partners, integrated our findings into more than 5 courses and countless co-curricular workshops, and generated a thriving research program resulting in 30 peer reviewed publications and conference presentations [e.g. 17, $28-$ 39].

In both cases, our research has enhanced the understanding and practice of engineering leadership education-driving pedagogical innovation, experiential learning, grounded theory, and knowledge mobilization. How did two small projects lay the groundwork for a stable and impactful research program? At the risk of oversimplifying a complex process - it began with the entrepreneurial spirit of a Department Chair-Professor Doug Reeve-who saw a gap he wanted to fill in engineering education. In the absence of traditional funding mechanisms, he found ways to make it happen through co-curricular programing, elective courses, graduate student supervision, research and outreach. He used a combination of Faculty-based seed grants, an industry-based community of practice, deep institutional knowledge, extensive networks and philanthropy to fill the gap, deliberately hiring and supervising educators and researchers from a range of disciplinary backgrounds. The seeds Doug planted fifteen years ago have since taken root in our classrooms, scholarly communities, and industry settings - through the efforts of a growing team of faculty, staff, sessional instructors and students. Our organizational growth from entrepreneurial chair to named institution (employing 22 faculty, staff and sessional instructors) demands a new organizational strategy.

Our new Director, Professor Emily Moore-with nearly 30 years of experience in industry and technical research-is in an excellent position to support our transition from fledgling, entrepreneurial program to foundational member of a new institute: The Institute for Studies in Transdisciplinary Engineering Education and Practice (ISTEP). She has led a consolidation and rearticulation of our program offerings and objectives, increased our partnership with the university's Engineering Career Centre, and is developing new mechanisms to mobilize our research into industrial practice through our COP partners and our provincial engineering society. Her work is cementing the institutional funding model within the faculty and exploring new business models to expand 
our COP and fund a research program that is working with multiple faculty on a theme-based model with increased student participation.

In the end, the story of our maturing research program is not simply a narrative of two disciplines engaging in parallel play, but rather a successful organizational initiative to transcend traditional silos in Canada separating academia from industry and the social sciences and humanities from the natural sciences and engineering. The strategic institutional efforts of our founding Director and current Director, along with the interdisciplinary efforts of our faculty members, full time staff, sessional instructors, and student team deserve as much attention as the findings themselves. We look forward to continued learning, curricular innovation and university-industry partnerships as we transition from entrepreneurial start-up to selfsustaining institution, building on the strengths of our interdisciplinary foundations.

\section{LEARNING FROM THESE APPROACHES}

While each approach to developing Engineering Leadership in this work is unique, there are many unifying tools and themes. These include utilizing industry practices to ground academic approaches, deploying novel ways to incentivize students' engagement in programming, examining engineering leadership development using lenses common in other areas of the education literature (e.g. academic plans and identity development), and using robust research design to inform curricular and cocurricular programming. Taken together, utilizing all of these approaches might be overwhelming to the engineering educator interested in providing their students with greater opportunities for engineering leadership development. However, it is not our intent that all, or even a majority, of these approaches be rapidly adopted by any one program. After all, the work presented here represents tens of thousands of person hours spent in design, development, testing, implementation, and refinement.

Instead, our hope is that the breadth of approaches presented provides all interested parties at least one tool that can be easily adapted to any unique situation at their institution and quickly adopted. Through sharing these best practices, we hope to accelerate the development of engineering leadership across as many engineering students as possible on a global basis. After all, the unifying theme underlying all of the work discussed here is a belief that we will all benefit when more engineers are ready to lead effectively in all sectors of society.

\section{CONCLUSION AND FUTURE WORK}

For all of the programs discussed here, future work entails continuing both the academic and research programs, while gathering additional data to enable further refinement of best practices and perhaps even yield unifying definitions of engineering leadership. In addition, this work represents the beginning of a new layer of international collaboration. This new work includes deployment of research protocols developed at one program to partner settings. We look forward to seeing what will come from new streams such as the exploration of engineering leadership identity development in an Australian setting or development of new industry partnerships that form new communities of practice.

\section{Acknowledgements}

Funding and support for parts of this work come from several sources, including from members of the Engineering Leadership Community of Practice, institutional support from the University of Toronto, SSHRC, OHCRIF and the National Science Foundation (NSF). NSF support comes under Grant Number EEC1664231 through the Research in the Formation of Engineers program. Any opinions, findings, and conclusions or recommendations expressed in this material are those of the authors and do not necessarily reflect the views of the NSF.

\section{References}

1. Graham, R., Educating tomorrow's engineering leaders What do we really mean by 'engineering leadership', how can it be developed and nurtured? Materials Today, 2009. 12(9): p. 6-6.

2. Graham, R., Engineering leadership education: A snapshot review of international good practice (white paper). 2009: Bernard M. Gordon- MIT Engineering Leadership Program. 41.

3. Passow, H.J., Which ABET competencies do engineering graduates find most important in their work? Journal of Engineering Education, 2012. 101(1): p. 95-118.

4. Lattuca, L.R. and J.S. Stark, Shaping the college curriculum: Academic plans in context. 2011: John Wiley \& Sons.

5. Donald, J. and M. Klassen. Comparing engineering leadership curricula in Canada and the United States: The role of external and internal influences. in IEEE Frontiers in Education. 2018. San Jose, CA: IEEE.

6. Klassen, M. and J. Donald, Developing a Taxonomy to Compare Engineering Leadership Curricula Across Canadian Universities. Canadian Journal of Science, Mathematics and Technology Education, 2020, in press: p. 1-16.

7. Klassen, M. and J. Donald, Using an Academic Plan Model to Analyze Canadian Engineering Leadership Curriculum. Proceedings of the Canadian Engineering Education Association (CEEA), 2018.

8. Sinar, E., et al., High-Resolution Leadership: A Synthesis of 15,000 Assessments into How 
Leaders Shape the Business Landscape. 2016: Pittsburgh, PA.

9. United Nations. UN Sustainable Development Goals. n.d. [cited 2019 31st May]; Available from:

https://www.un.org/sustainabledevelopment/sust ainable-development-goals/.

10. National Academy of Engineering. Grand Challenges for Engineering. n.d. [cited 2019 31st May ]; Available from: http://www.engineeringchallenges.org/.

11. McCauley, P., Essentials of Engineering Leadership and Innovation. 2017, Boca Raton: CRC Press.

12. Schell, W.J., B.E. Hughes, and B. Tallman. Exploring the Conflict Between an Engineering Identity and Leadership. in Canadian Engineering Education Association Annual Conference. 2018. Vancouver, BC, Canada.

13. Schell, W.J., B.E. Hughes, and B. Tallman. Understanding the Perceived Impact of Engineers' Leadership Experiences in College. in American Society for Engineering Education International Annual Conference. 2018. Salt Lake City, UT.

14. Hughes, B.E., W.J. Schell, and B. Tallman. Development of Leadership Self-Efficacy: Comparing Engineers, Other STEM, and NonSTEM Majors. in FIE 2018 Conference Proceedings. 2018. San Jose, CA.

15. Hughes, B.E., W.J. Schell, and B. Tallman, Understanding Engineering Identity In Undergraduate Students, in ASEM International Annual Conference. 2018: Coeur d'Alene, ID.

16. Schell, W.J. and B.E. Hughes. Are Engineers Leadership Attitudes and Experiences Different than Other Students? in ASEM International Annual Conference. 2017. Huntsville, AL.

17. Rottmann, C., R. Sacks, and D.W. Reeve, Engineering leadership: Grounding leadership theory in engineers' professional identities. Leadership, 2015. 11(3): p. 351-373.

18. Tallman, B., et al., How Do Engineering Undergraduates Define Engineering Identity?, in ASEM International Annual Conference. 2019: Philadelphia.

19. Schell, W.J., et al., How Do Students View Leadership Identity in Engineering?, in AustralAsian Engineering Education Conference. 2019: Bisbane, Australia.

20. Kwapisz, M., et al., The Effect of Engineering Leadership Identity Research on the Identities of Student Researchers, in ASEM International Annual Conference. 2019: Philadelphia.

21. Evans, G.J., et al. Incorporating teameffectiveness as a learning objective in the design project within a technical core course. in Canadian Engineering Education Association Conference. 2013. Montreal, QC.

22. Sheridan, P.K., et al. A team-effectiveness inventory for guided reflection and feedback. in American Society for Engineering Education Conference and Exposition. 2013. Atlanta, GA.

23. Sheridan, P.K., G. Evans, and D. Reeve, Teaching Team Effectiveness in Large Classrooms. 2015, in review, Higher Education Quality Council of Ontario (HEQCO): Toronto, ON.

24. Sheridan, P.K., G.J. Evans, and D.W. Reeve. Understanding teaching assistants' assessment of individual teamwork performance. in American Society of Engineering Education Annual Conference and Exposition. 2014. Indianapolis, IN.

25. Sheridan, P.K., et al. The role of "togethering" in developing teamwork relationships and shared meaning. in American Society of Engineering Education Annual Conference and Exposition. 2015. Seattle, WA.

26. Sheridan, P.K., D.W. Reeve, and G.J. Evans. Selfand peer-assessments of team-effectiveness in a first year engineering design course. in Canadian Engineering Education Association Conference. 2012. Winnipeg, MB.

27. Sheridan, P.K., D.W. Reeve, and G.J. Evans. $A n$ on-line team-effectiveness learning system. in Canadian Engineering Education Association Conference. 2014. Canmore, Alberta.

28. Reeve, D.W., C. Rottmann, and R. Sacks. A responsibility to promote leadership: Engineering entrepreneurs speak back to resistance. in Canadian Engineering Education Association Conference. 2014. Calgary, Alberta.

29. Reeve, D.W., C. Rottmann, and R. Sacks. The ebb and flow of engineering leadership orientations. in American Society of Engineering Education Annual Conference and Exposition. 2015. Seattle, WA.

30. Reeve, D.W., et al. Engineer leadership in organizations and the implications for curriculum development. in Canadian Engineering Education Association Conference. 2013. Montreal, QC.

31. Rottmann, C., et al., An intersubjective analysis of engineering leadership across organizational locations: Implications for higher education. Canadian Journal of Higher Education, 2016. 46(4): p. 146-173.

32. Klassen, M., et al., Engineering: Moving leadership from the periphery to the core of an intensely technical curriculum, in New Directions for Student Leadership, S.R. Komives and M.J. Sowcik, Editors. In Press, Wiley. 
33. Kovalchuk, S., et al. Transitioning from university to employment in engineering: The role of curricular and co-curricular activities. in American Society of Engineering Education Annual Conference and Exposition 2017. Columbus, $\mathrm{OH}$.

34. Kovalchuk, S., et al. Perceived importance and confidence in leadership ability: A national survey of final year Canadian engineering students. in American Society for Engineering Education Annual Conference and Exposition. 2019. Tampa, FL.

35. Liu, Q., et al. Engineering co-op and internship experiences and outcomes: The roles of workplaces, academic institutions and students. in Canadian Engineering Education Association 2018. Vancouver, BC.

36. Liu, Q., et al. Engineering co-op and internship experiences and outcomes: The roles of wokrplaces, academic institutions and students. in Canadian Engineering Education Association Annual Conference. 2018. Vancouver, BC.

37. Rottmann, C., et al. Examining the engineering leadership literature: Community of practice style. in American Society of Engineering Education Annual Conference and Exposition. 2018. Salt Lake City, UT.

38. Rottmann, C., et al. Counting past two: Engineers' leadership learning trajectories. in American Society of Engineering Education Annual Conference and Exposition. 2019. Tampa, FL.

39. Rottmann, C., et al. Sports, arts and concrete canoes: Engineers learning to lead outside the formal curriculum. in American Society of Engineering Education's 123rd Annual Conference and Exposition. 2016. New Orleans, LA.

40. Chan, A., et al. Wisdom through adversity: Situated leadership learning of senior engineers. in American Society for Studies in Engineering Education Anual Conference \& Exposition. 2020. Montreal, QC.
41. Rottmann, C., et al. We did it! Proud moments as a catalyst for engineers' leadership learning. in Candian Engineering Education Association Annual Conference. 2020. Montreal, QC.

42. Rottmann, C. and D. Reeve, Equity as rebar: Bridging the micro/macro divide in engineering ethics education. Canadian Journal of Science, Mathematics and Technology Education, 2020. 20(1).

43. Rottmann, C., et al. Engineering ethics education: More than a CEAB requirement. in Canadian Engineering Education Association Annual Conference. 2015. Hamilton, ON.

44. Rottmann, C., et al. Where's my code? Engineers navigating ethical issues on an uneven terrain. in American Society of Engineering Education Annual Conference and Exposition. 2018. Salt Lake City, UT.

45. Rottmann, C., et al. Gendering engineering leadership: Aspirations vs. shoulder tapping in American Society of Engineering Education Annual Conference and Exposition. 2015. Seattle, WA.

46. Klassen, M., et al. Charting the landscape of engineering leadership education in North American universities. in American Society of Engineering Education Annual Conference and Exposition. 2016. New Orleans, LA.

47. Reeve, D.W., et al., Curricular and co-curricular leadership learning for engineering students. Collected Essays on Learning and Teaching, 2015. 8(1): p. 41-56.

48. Simpson, A.E., G.J. Evans, and D.W. Reeve, $A$ summer leadership development program for chemical engineering students. Journal of Leadership Education, 2012. 11(1): p. 222-232.

49. Simpson, A.E., et al. Engineering leadership education: Catalyzing long term personal and professional growth. in Canadian Engineering Education Association Annual Conference. 2019. Ottawa, ON. 